\title{
CRITICAL RANGES OF SOME COMMERCIAL NICKEL STEELS
}

By Howard Scott

CONTENTS

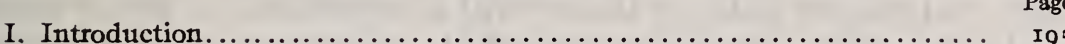

II. Previous observations on the critical temperatures of iron-carbon-nickel

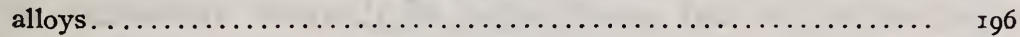

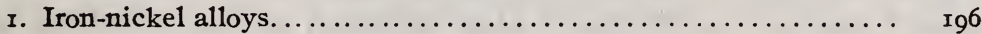

2. Medium carbon nickel steels....................... 197

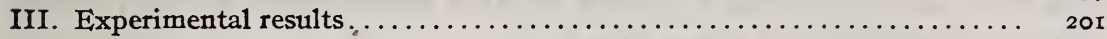

IV. Interpretation and application of experimental data............... 208

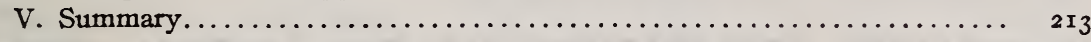

\section{INTRODUCTION}

The great advances made in mechanical engineering during recent years through the use of alloty steels, as illustrated in the development of the airplane and automobile, may be ascribed primarily to the application of nickel as an alloying element. The ternary system iron-carbon-nickel has a wide industrial application and forms the fundamental basis of the even greater class of the widely used quaternary steels, such as nickel chromium, nickel silicon, and nickel vanadium. As is not uncommon with such cases of virile growth in an industry, the application of the alloy steel in a largely empirical manner has outstripped its scientific development, so that a fertile field for metallographic research still remains. In this field the basic nickel steels require first consideration and are the subject of the present investigation, which is offered as a preliminary to the study of the more complex alloys of industrial importance.

Of the principal tools of metallography-microscopic examination, determination of mechanical properties, and thermal analysis-the last-named has developed much more slowly in its application to industrial needs, so that heat-treatment operations are often still based on empirically determined temperatures-that is, temperatures determined without regard to the actual transformation characteristics of the alloy. This situation is undesir- 
able, since there is no uniform standard for comparison of results. It is due, outside the usual difficulties involved in temperature measurements, to the pioneer character of much of the published work, to the lack of definiteness of the $\mathrm{Ac}_{3}{ }^{1}$ transformation, particularly in low-carbon steels, to the failure to define operating conditions completely, and to the paucity of information correlating thermal characteristics with results of heat treatment.

In pursuing the present investigation the foregoing difficulties were recognized, and where possible precautions were taken to eliminate them, with the object in view of collecting transformation-temperature data for the several compositions of nickel steels available at the Bureau of Standards, as a basis to aid in the standardization and specification of thermal treatments for the nickel steels. A review is also included of the previous work in this field, and attention is called to such phenomena as are related to the constitution of these steels.

\section{PREVIOUS OBSERVATIONS ON THE CRITICAL TEM- PERATURES OF IRON-CARBON-NICKEL ALLOYS}

The previous investigators in this field have presented criticaltemperature data on nickel steels obtained by the use of thermal analysis and also by employing the change in several of the physical properties as a criterion of allotropic change. The former method has been confined chiefly to steels having an appreciable $A_{1}$ transformation and the latter to iron-nickel alloys.

\section{IRON-NICKEL ALLOYS}

The attention of most experimenters seems to have centered on these alloys, due, no doubt, to their peculiar properties and theoretical significance. There is therefore considerable material available in this field.

The principal investigations ${ }^{2}$ have been those of Hopkinson, Osmond, Dumas, Guertler and Tammann, and Honda and Takagi, who used the changes in the magnetic state as a criterion of phase change. Boudouard ${ }^{3}$ has used thermoelectric power and Chevenard ${ }^{4}$ expansion in the same way.

\footnotetext{
${ }^{1} \mathrm{AC}$ and $\mathrm{Ar}_{3}$ are used in the text to indicate this transformation, whether above or below the maximum of $\mathrm{A}_{2}$.

2 Hopkinson, Proc. Royal Soc., London, 48, pp. I-I3; x890. Osmond, Compt. Rend., 128, pp. 304-307: 1899. Dumas, Fig. 89, p. 27 I of Guillet's text, Êtude Industrielle des Alliages Métalliques. Guertler and Tammann, Zeit. f. Anorg. Chem., 45, p. 205; 1905. Honda and Takagi, Sci. Rep. Tohoku Imp. Univ., 6. p. 321; 1917 .

3 Boudouard, Iron and Steel Inst., 63, p. 299; $x 903$.

- Chevenard, Rev. de Met., 11, pp. 84I-863; г9г4.
} 
The results of Honda and Takagi, being the most recent and apparently the most consistent, have been plotted in Fig. $x$. Unfortunately they have not given actual analyses of the material used, so their results have not the weight that such careful experimental work deserves.

The curve for $\mathrm{Ar}_{3}$ in Fig. I as drawn indicates that $\mathrm{Ar}_{3}$ occurs at absolute zero for a nickel content between 32 and 33 per cent, while the work of Chevenard ${ }^{5}$ indicates that this transformation would be entirely complete at absolute zero for a nickel content between 34 and 35 per cent. This is good agreement, considering that different experimental methods have been used, and the very in teresting conclusion seems justifiable that above 34 per cent nickel the iron at all temperatures is in the gamma state. This critical composition corresponds remarkably closely to that of $\mathrm{Fe}_{2} \mathrm{Ni}(34.45$ per cent $\mathrm{Ni}$ ).

\section{MEDIUM CARBON NICKEL STEELS}

In this most interesting field of steels having

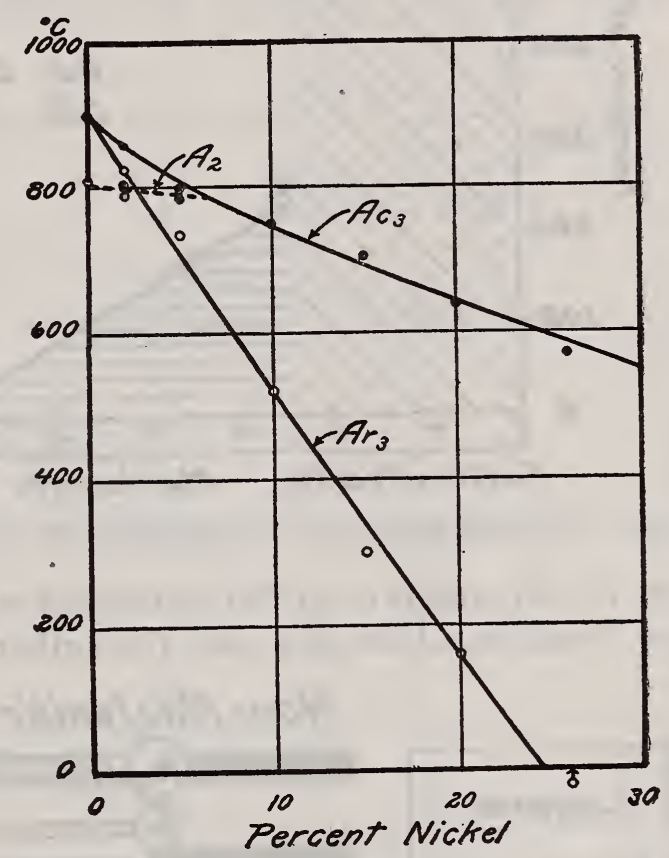

FIG. I.-Transformation temperatures of iron-nickel alloys determined magnetically by Honda and Takagi

a distinct $A_{1}$ transformation, two researches ${ }^{6}$ of considerable value are available, namely, those of Dejean and of Carpenter, Hadfield and Longmuir. The value of the contribution by the former author lies in the interpretations given to the thermal critical temperatures obtained from 0.20 per cent carbon steels of various nickel contents, and that of the latter authors lies in the more complete information given on variable nickel steels of 0.40 to 0.50 per cent carbon content.

\footnotetext{
5 Chevenard, Rev. de Met., 11, p. 84I; I9r4.

- Dejean, Rev. de Met., 14, pp. 641-675; 1917. Carpenter, Hadfield, and Longmuir, 7 th Report Alloys Research Committee, Proc. Inst. Mech. Eng., 4, p. 857; 1905.
} 
The cooling-curve data of Dejean as plotted by him are reproduced in Fig. 2, with changes only in the notation of his points

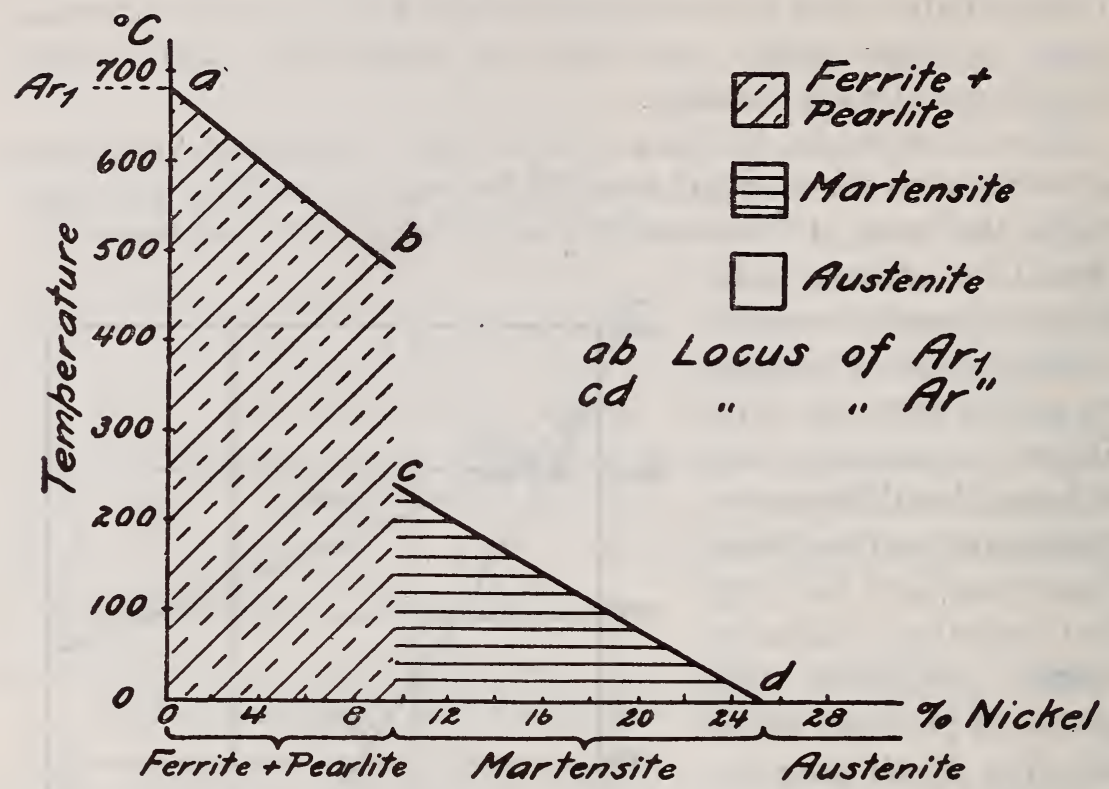

FIG. 2.-Effect of nickel on the Ar critical ranges of 0.20 per cent carbon steels. (Dejean)

of $A$ to $\mathrm{Ar}_{1}$ and $B$ to $\mathrm{Ar}^{\prime \prime}$ in accordance with the notation ${ }^{7}$ adopted by Portevin, Chevenard, and the author for describing the same

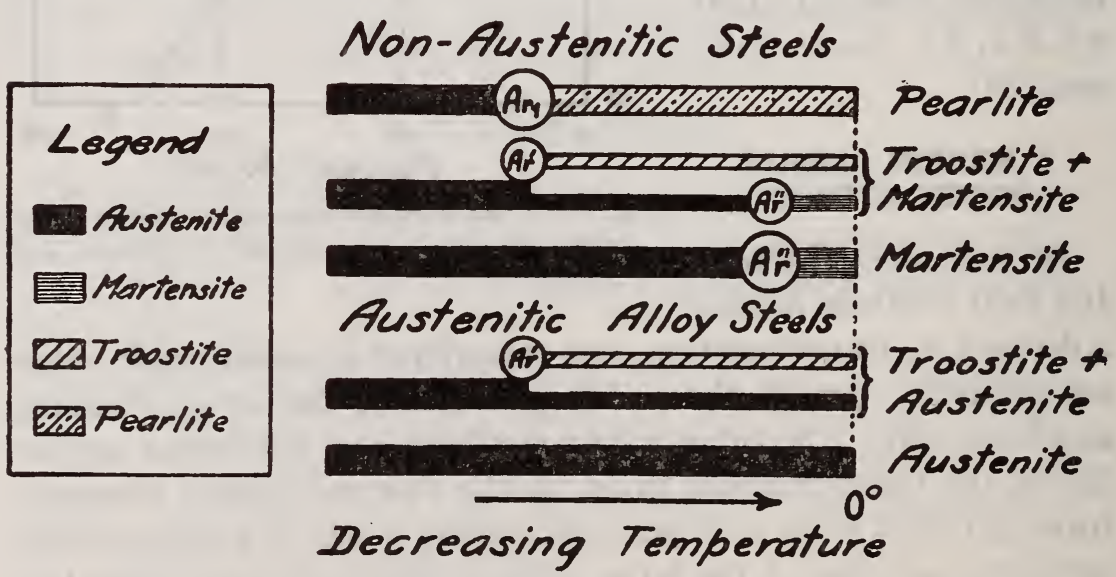

FIG. 3.-Diagram of constitutional changes in cooling steels. (Dejean)

phenomena as found in widely different steels. After showing that the transformation $\mathrm{Ar}_{1}$ of this figure represents the precipi-

${ }^{7}$ Portevin, Rev. de Met., 14, p. 707; 1917. Also preprint, Iron and Steel Inst.; Sept., r9r9. Chevenard,

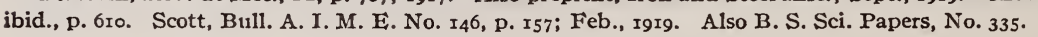


tation of cementite as troostite or a decomposition product, he says (p. 671):

There now remains to be determined the exact nature of the transformation occurring at point $B\left(\mathrm{Ar}^{\prime \prime}\right)$. The most universal opinion is that martensite is a metastable solid solution of cementite and ferrite or alpha iron. The point $B\left(\mathrm{Ar}^{\prime \prime}\right)$ thus, from the foregoing, corresponds to the transformation of gamma iron into alpha without the carbide, which was in the gamma iron, being thrown out of solution. Fundamentally the point $B\left(\mathrm{Ar}^{\prime \prime}\right)$ is the $\mathrm{Ar}_{3}$ point depressed.

Dejean $^{8}$ further illustrates these constitutional changes diagrammatically as reproduced in Fig. 3 with the same notational changes as in Fig. 2.

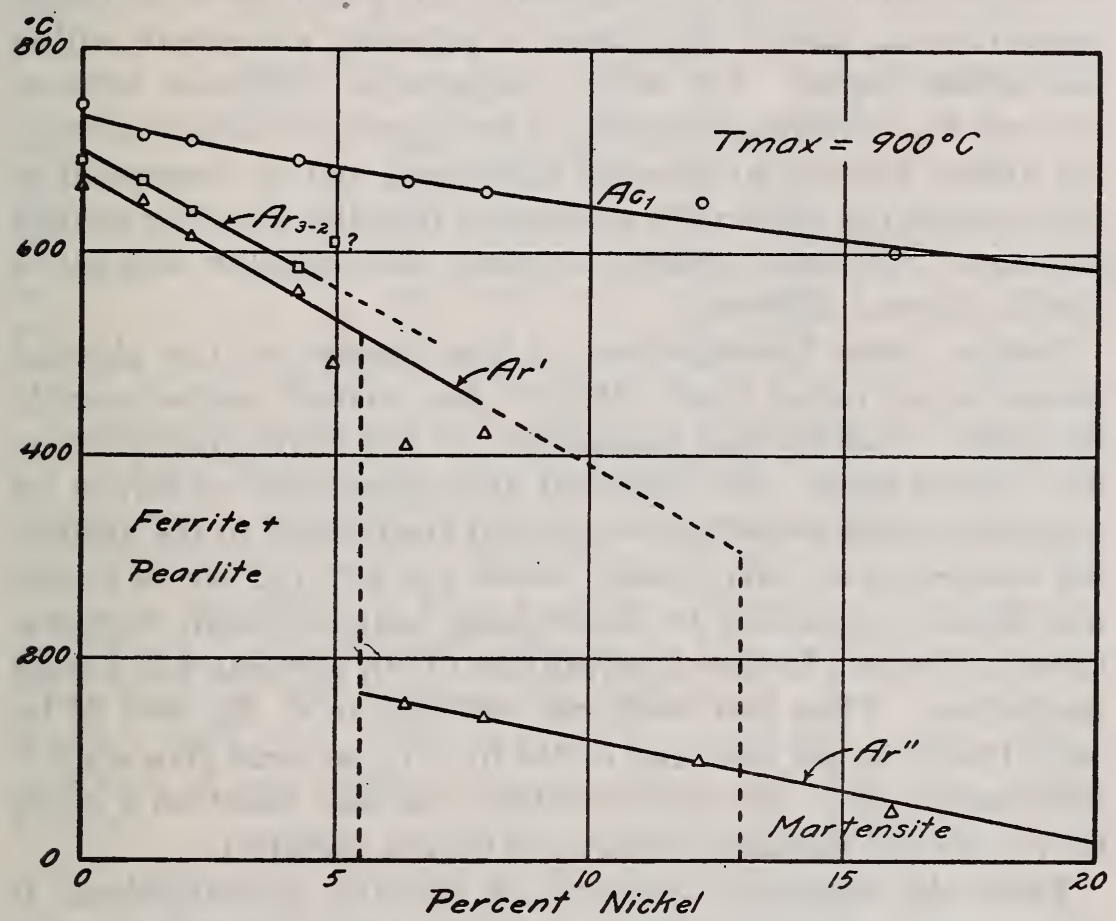

FIG. 4.-Effect of nickel on the thermal critical ranges of 0.40 to 0.50 per cent carbon steels from data of Carpenter, Hadfield, and Longmuir

The same phenomenon is well verified by the investigations of Carpenter, Hadfield, and Longmuir, already mentioned, although they offered no explanation of it. The transformation-temperature data from their tables have been plotted in Fig. 4, together with their observations on the microstructure of the same steels air cooled from above $\mathrm{Ac}_{3}$. A few corrections added to the values taken from the curves make the tabulated results comparable 
on the basis of observations taken from derived differential or inverse-rate curves. Unfortunately, the temperature of the $\mathrm{Ac}_{\mathbf{s}}$ transformation can not be estimated with any degree of certainty from the curves given.

In Fig. 4 the limits over which both martensite and troostite are found in the air-cooled samples have been indicated by dotted lines. Since Carpenter, Hadfield, and Longmuir did not examine microscopically their samples used for thermal study, it is impossible to set accurately the limits of the range of nickel content over which, for the rate of cooling adopted, both martensite and troostite will be found, or of the composition at which ferrite no longer separates out, though this latter is probably somewhere within the former region. The sharp temperature difference between $\mathrm{Ar}^{\prime}$ and $\mathrm{Ar}_{1}$, occurring between 4.5 and 9 per cent nickel contents, the author believes to be quite significant, and to correspond to the formation of appreciable amounts of troostite, since the marked structural difference between troostite and pearlite indicate a similar thermal difference.

Besides these investigations of the changes in the physical properties of nickel steels, Meyer ${ }^{2}$ has studied microscopically the effect of nickel and manganese on the ferrite precipitation for various steels. He observed the appearance of ferrite on quenching steels heated above $\mathrm{Ac}_{3}$ and then cooled to the quenching temperature. His results, which are for $\mathrm{Ar}_{3}$, are of course not directly applicable to determining heat-treatment temperatures and have a further disadvantage of not agreeing well among themselves. Thus two steels not differing in $\mathrm{C}, \mathrm{Ni}$, and $\mathrm{Si}$ by more than 0.02 per cent and in $\mathrm{Mn}$ by 0.13 per cent give a $30^{\circ} \mathrm{C}$ difference in $\mathrm{Ar}_{3}$. His generalizations are also based on a curve for $\mathrm{Ar}_{3}$ convex upward, which is, of course, incorrect.

From the foregoing summary of previous investigations, it is apparent that considerable work has been carried out on a wide range of compositions, and that the $A_{1}$ transformation only has been definitely defined. The present work covers only a limited range of compositions, which are, however, of great industrial importance. The aim of this study is to define more completely and precisely the transformation ranges of these low-nickel medium-carbon steels. 


\section{EXPERIMENTAL RESULTS}

The work was carried out on seven commercial steels of a nickel content ranging from o to 3.5 per cent, the proportion of other elements being fairly constant, and on a synthetic ironcarbon alloy made up at the Bur eau of Standards. ${ }^{10}$ The chemical compositions are given in Table $\mathrm{I}$.

TABLE 1.-Chemical Analysis of Steels Investigated

\begin{tabular}{|c|c|c|c|c|c|c|c|}
\hline Sample No. & $\begin{array}{l}\text { Per } \\
\text { cent } \\
\text { C }\end{array}$ & $\begin{array}{l}\text { Per } \\
\text { cent } \\
\mathbf{N i}\end{array}$ & $\begin{array}{l}\text { Per } \\
\text { cent } \\
\text { Mn }\end{array}$ & $\begin{array}{l}\text { Per } \\
\text { cent } \\
\text { Si }\end{array}$ & $\begin{array}{c}\text { Per } \\
\text { cent } \\
\mathbf{P}\end{array}$ & $\begin{array}{c}\text { Per } \\
\text { cent } \\
\text { S }\end{array}$ & Remarks \\
\hline F30.. & 0.40 & & & 0.008 & & & $\begin{array}{l}\text { Iron-carbon alloy impurities } \\
\text { probably less than } 0.04 \text { per } \\
\text { cent. }\end{array}$ \\
\hline C24... & .40 & 0.00 & 0.75 & .22 & 0.014 & 0.022 & \\
\hline A50.... & .38 & 2.00 & .66 & .16 & .017 & .011 & 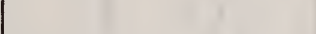 \\
\hline A49.................. & .35 & 2.04 & .65 & .17 & .010 & .020 & \\
\hline A58.................. & .35 & 2.68 & .64 & .24 & .014 & .022 & Nickel steels. \\
\hline A51.......... & .40 & 2.90 & .63 & .28 & .023 & .033 & 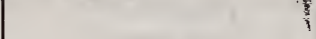 \\
\hline A52........... & .37 & 3. 00 & .71 & .22 & .012 & .010 & \\
\hline A53............ & .29 & 3.46 & .56 & .28 & .018 & .028 & \\
\hline
\end{tabular}

The thermal curves of these steels were obtained on samples of I.5 to $2.0 \mathrm{~g}$ mass. The apparatus employed and the details of manipulation have been described somewhat in detail elsewhere. ${ }^{11}$ Several runs were taken on each composition, and a curve typical of each is reproduced in Figs. 5 and 6 to illustrate the interpretation of the various thermal inflections. The temperature values taken from all the curves as illustrated are given in Table 2, together with such other data as are essential to the precise definition of the critical points. When, however, the transformation $A_{1}$ showed a decalescence or recalescence, which was only in the case of the steels not containing nickel, the temperature of the beginning of the reversal was then taken as the maximum. The intensity of this phenomenon as observed in the carbon steels is given in Table 3 .

The difficulty already mentioned of locating $\mathrm{Ac}_{3}$ is apparent from an inspection of Figs. 5 and 6 . This is due to its position, i. e., a superimposing on the end of $A c_{1}$, and to its attenuated character. It may, however, be brought out with maximum sharpness by a suitable choice of heating rate-a decrease of rate causes a more pronounced inflection, as illustrated by the second

\footnotetext{
10 Cain, Schramm, and Cleaves, B. S. Sci. Papers, No. 266.

11 Scott and Freeman, Bull. Am. Inst. of Min. and Met. Engrs., No. 152, p. 1429, August, 1919. Also B. S. Sci. Papers, No. 348 .
} $159393^{\circ}-20-2$ 
and fourth heatings of $\mathrm{A}_{5} 8$ (Fig. 5). There is, however, a practicable limit to the benefit derived, due to the increased variability of the time readings with increasing time interval. This limit is reached for the apparatus employed at a rate of about $0.05^{\circ} \mathrm{C}$ per second, for which rate the individual readings are likely to be too variable to show the $\mathrm{Ac}_{3}$ inflection clearly.

From the foregoing the values of the $\mathrm{Ac}_{3}$ transformation temperatures might be expected to be somewhat inconsistent, but

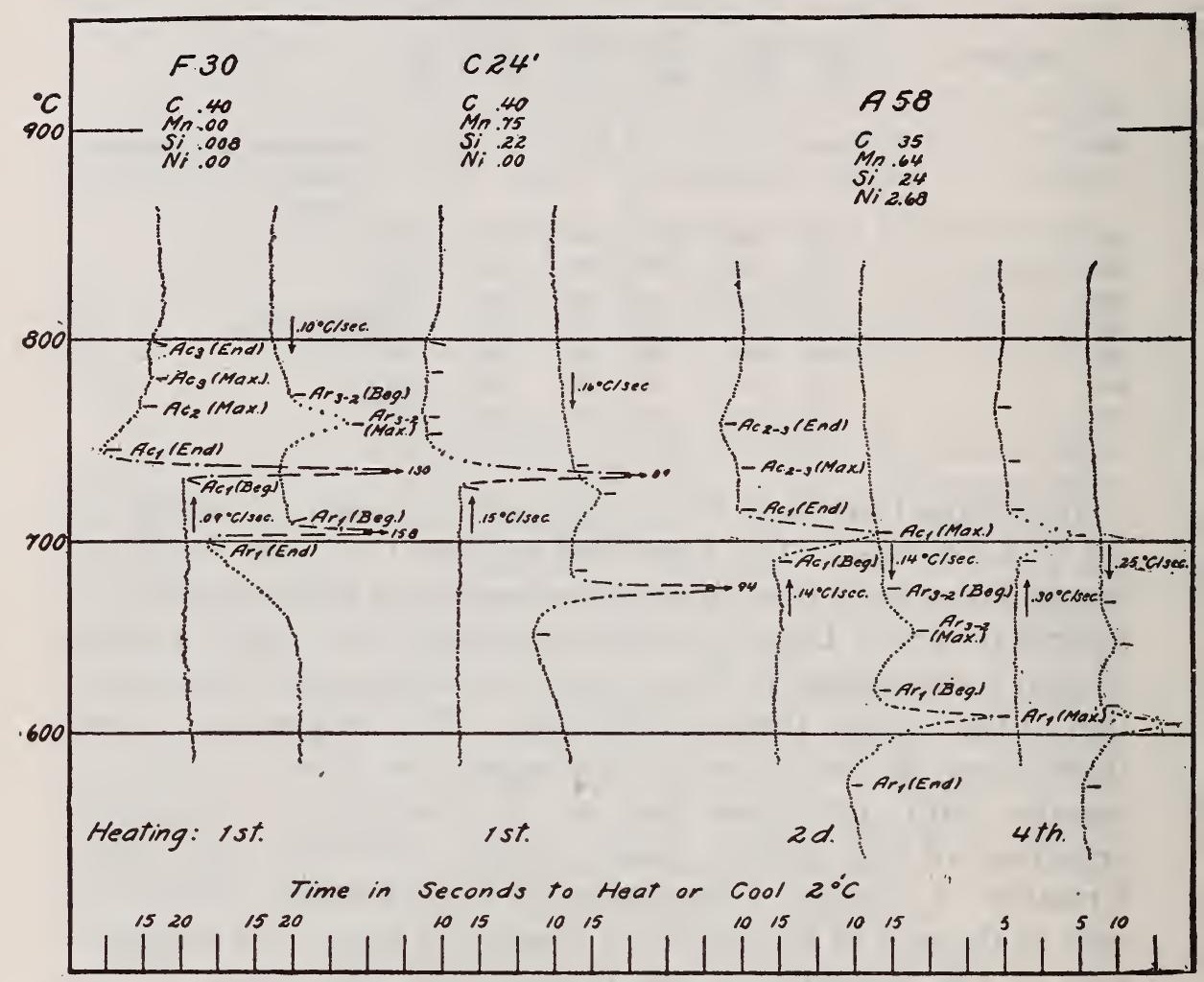

FIG. 5.-Thermal curves of carbon and nickel steels

this is not the case, for there is very good agreement between the various curves as shown by Fig. 7 and Table 2. As a matter of fact the more definite Ar transformations are less consistent than the Ac. This should not be ascribed to an inexplicable variability of critical points, as it is not unusual, but to actual constitutional differences in the metal due largely, no doubt, to previous heat treatment. Thus, the first cooling of $\mathrm{C}_{24}$ and $\mathrm{C}_{24} 4^{\prime}$, duplicate samples, shows $\mathrm{Ar}_{1} 6^{\circ}$ and $4^{\circ} \mathrm{C}$, respectively, above the average. Microscopic examination of the steel in the initial state and after 


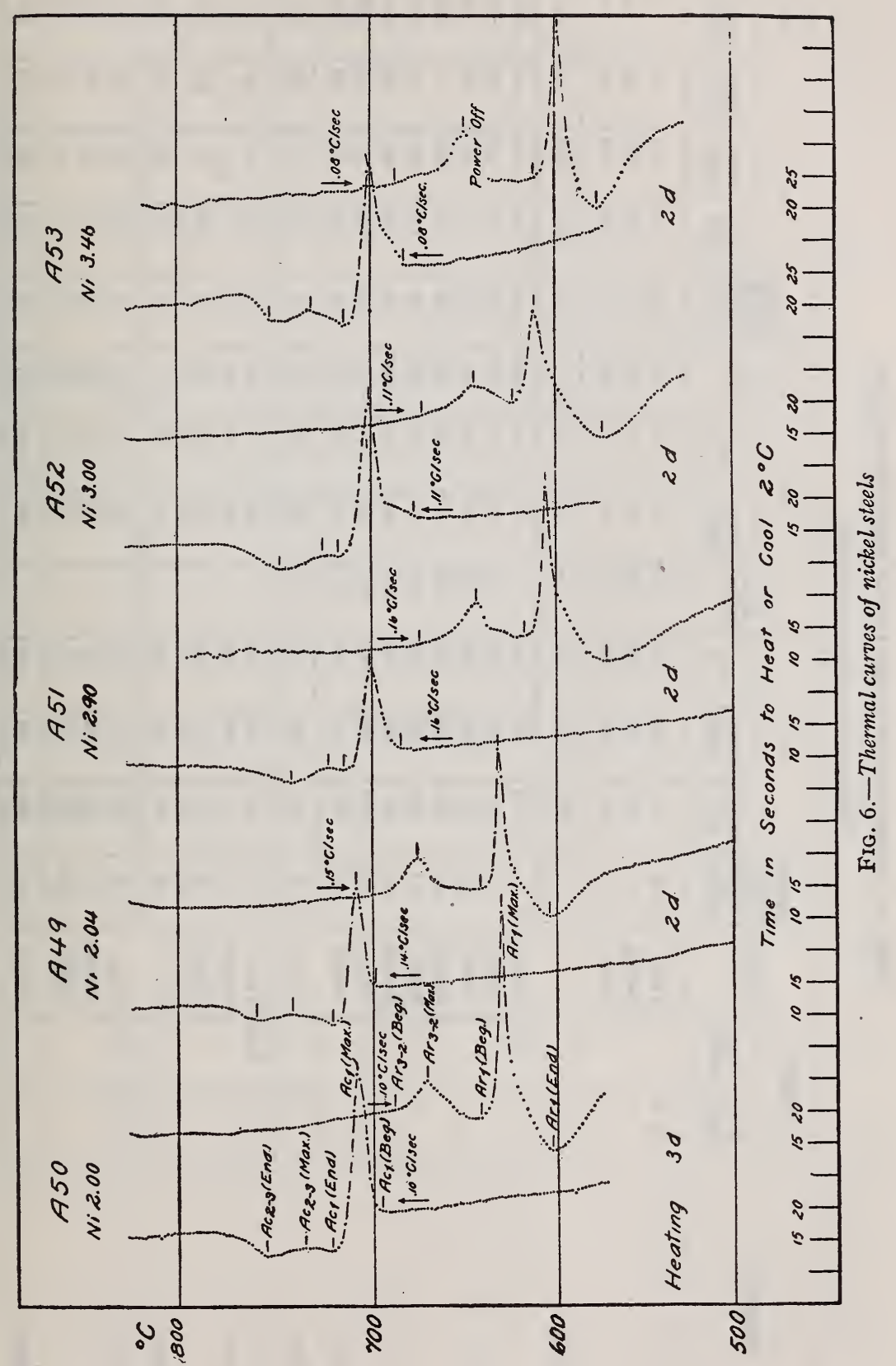




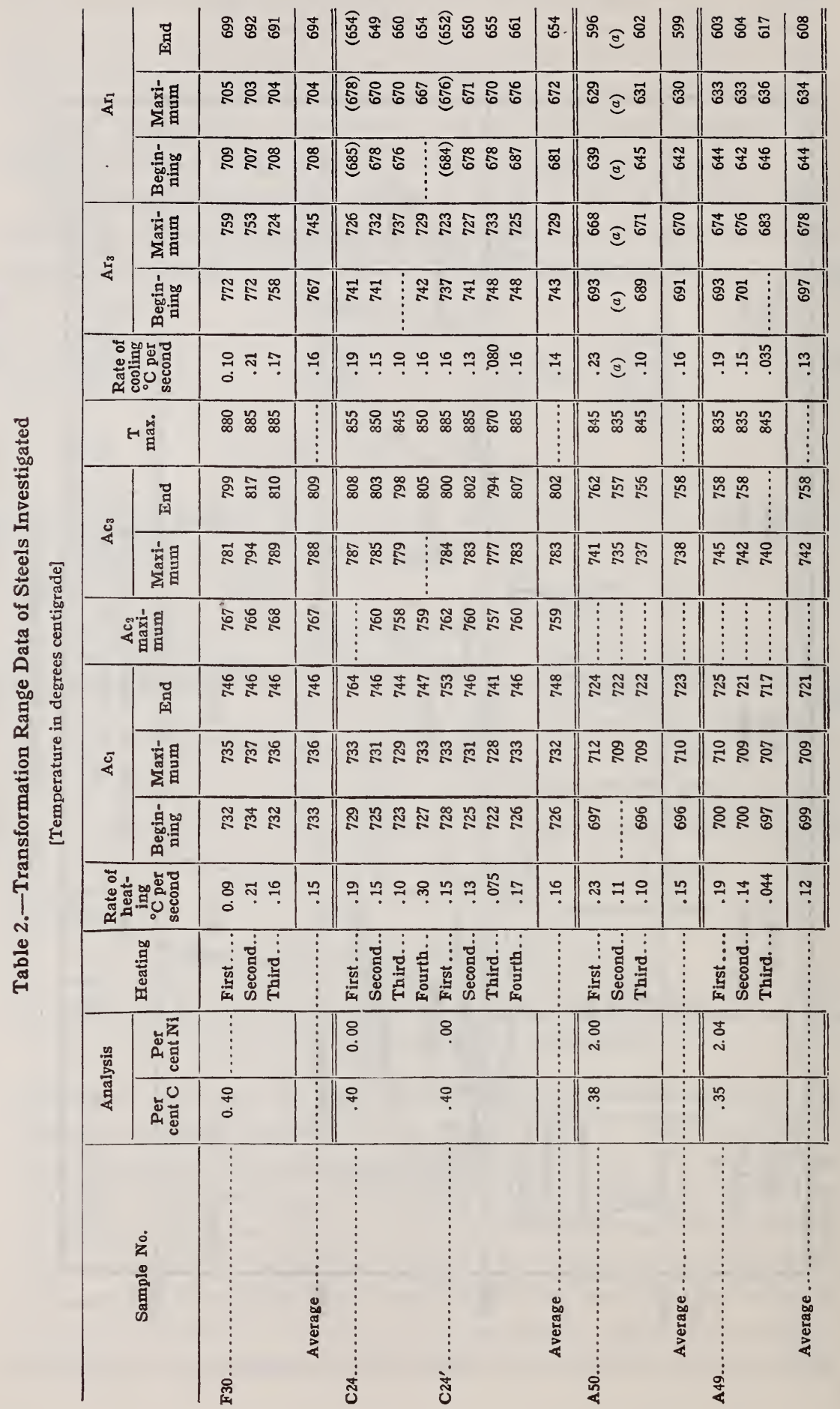




\begin{tabular}{|c|c|c|c|c|c|c|}
\hline 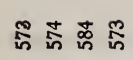 & io & ㄷำ & is & 오ํ & & 용ํํำ \\
\hline 吉苔吉: & $\bar{E}$ & $: 8$ & : & 영 & $\xi$ & 号金 \& \\
\hline 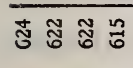 & $\vec{\sigma}$ & 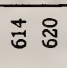 & $\overline{\hat{\sigma}}$ & : & 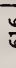 & $8 \%$ \\
\hline 荇 落 & 产 & 要苦 & 声 & 鄵志 & 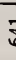 & 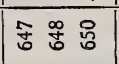 \\
\hline 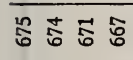 & $\tilde{\Xi}$ & : & : & : & 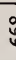 & : \\
\hline 푼웅 오․ & 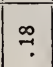 & بִ جִ ج & $?$ & $\stackrel{2}{9}=$ & & | \\
\hline 总品怘 & & 용용요 & & 웅 年 & & 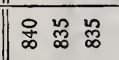 \\
\hline
\end{tabular}

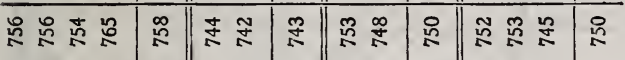

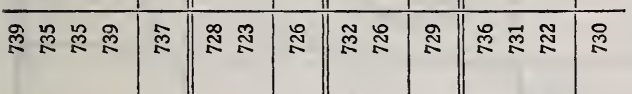

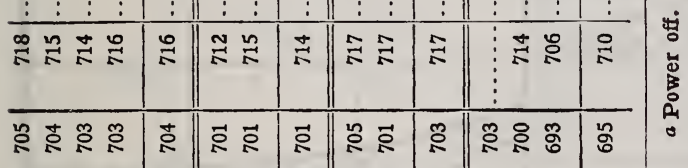

\begin{tabular}{|c|c|c|c|c|c|c|c|}
\hline 영 영 잉 영 & $\vec{\sigma}$ & \% & $\stackrel{\circ}{\circ}$ & 䒿荅 & ळ & 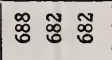 & 莺 \\
\hline 49 & ? & ㄱ. & $\stackrel{\infty}{?}$ & : & $\because$ & 웡 & 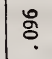 \\
\hline
\end{tabular}

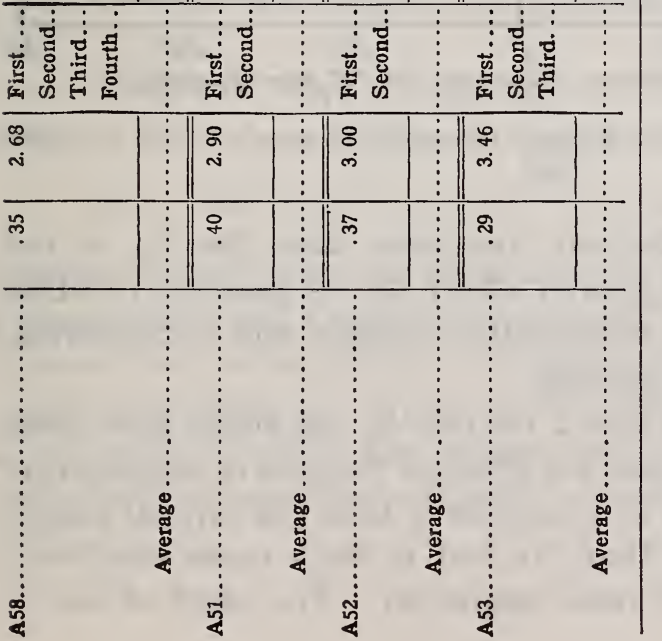


taking the thermal curves showed that the structure in the former condition was quite coarse, while in the latter it was very fine. In this connection the behavior of $\mathrm{Ar}_{3}$ for the iron-carbon alloy is also peculiar, the maximum being distinctly lower after each successive heating. As yet a satisfactory explanation of this can not be offered. That the $\mathrm{Ar}_{1}$ transformation should be more

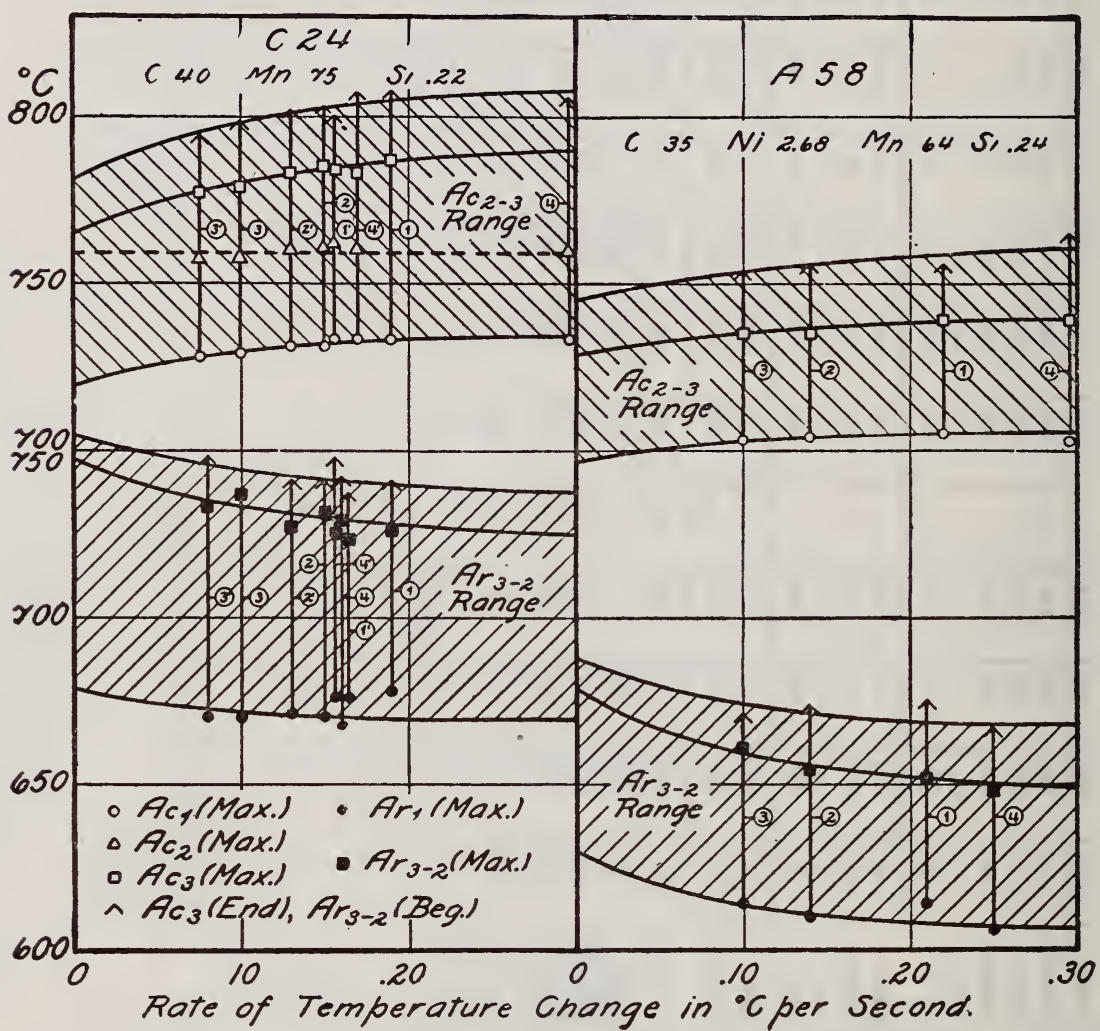

Fig. 7.-Effect of rate of temperature change on the critical ranges of a carbon and nickel steel

susceptible to previous thermal treatment than the $A c_{1}$ is not surprising in view of the greater effect on its position of other variables, such as rate of temperature change and composition, as shown in the following sections.

The principal data of Table 2 on two of the steels have been collected in Fig. 7 to illustrate the effect of the rate of temperature change. From this figure it is apparent that the critical ranges Ac are much less affected than Ar, but in both cases they vary linearly over the range of rates employed. The effect of rate is 
slight, so the values for each composition as given in Table 2 are averaged.

These average values for the same points as given in Fig. 7 have been plotted against per cent nickel in Fig. 8; the values for zero nickel are those taken from the carbon-steel $\mathrm{C}_{24}$. The curves are drawn to approximate conditions for 0.40 per cent $\mathrm{C}$ steel and an

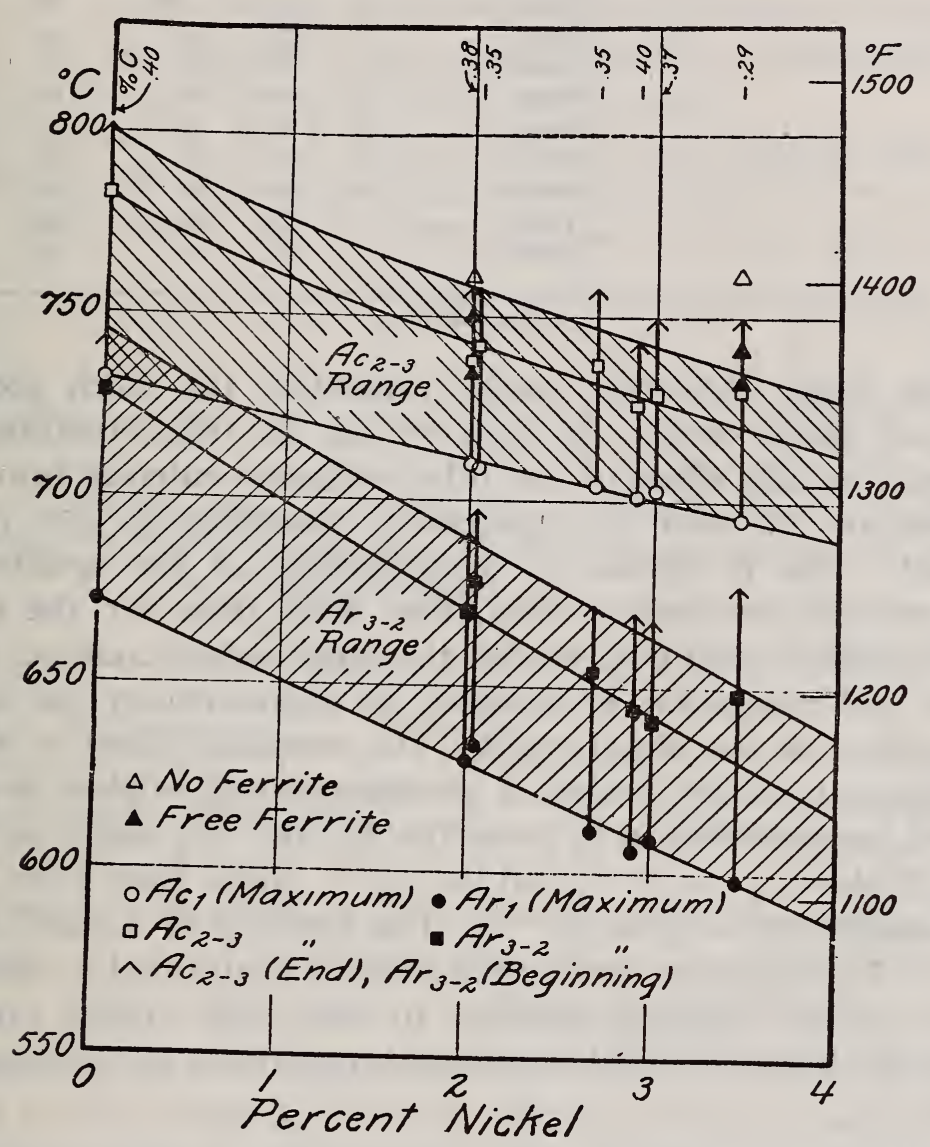

FIG. 8.-Effect of nickel on the critical ranges of 0.40 per cent carbon steel

average rate of temperature change of $0.15^{\circ} \mathrm{C}$ per second. The structure of small specimens quenched in water after a 1o-minute exposure at the temperature indicated was determined by microscopic examination. These results also are indicated in Fig. 8 as triangles, of which the hollow ones represent a purely martensitic structure, and the solid ones a martensitic matrix containing free ferrite. 
TABLE 3.-Intensities of Decalescence and Recalescence Effects Observed

\begin{tabular}{|c|c|c|c|c|c|}
\hline Sample No. & Heating & $\begin{array}{l}\text { Rate of } \\
\text { heating } \\
{ }^{\circ} \mathrm{C} \text { per } \\
\text { second }\end{array}$ & $\begin{array}{l}\text { Decales- } \\
\text { cence }{ }^{\circ} \mathrm{C}\end{array}$ & $\begin{array}{l}\text { Rate of } \\
\text { cooling } \\
{ }^{\circ} \mathrm{C} \text { per } \\
\text { second }\end{array}$ & $\begin{array}{l}\text { Recales- } \\
\text { cence }{ }^{\circ} \mathrm{C}\end{array}$ \\
\hline \multirow[t]{3}{*}{ F30.. } & First... & 0.09 & (a) & 0.10 & 4.3 \\
\hline & Second.... & .21 & 1.8 & .21 & 3.7 \\
\hline & Third.... & .16 & 1.9 & .17 & 1.8 \\
\hline \multirow[t]{4}{*}{ C24... } & First.... & .19 & (a) & .19 & .3 \\
\hline & Second... & .15 & (a) & .15 & .2 \\
\hline & Third..... & .10 & (a) & .10 & .8 \\
\hline & Fourth.... & .30 & (a) & .16 & .5 \\
\hline \multirow[t]{4}{*}{ C24'... } & First..... & .15 & (a) & .16 & (a) \\
\hline & Second.... & .13 & (a) & .13 & 1.0 \\
\hline & Third.... & .075 & (a) & .08 & .4 \\
\hline & Fourth.... & .17 & (a) & .16 & 1.0 \\
\hline
\end{tabular}

$a$ None observed.

From these and other curves presented, the much greater effect of nickel on the Ar than on the Ac transformations is evident, but the effect of the other elements entering into the composition of steel in appreciable quantities is also quite marked. This is shown by a comparison of the results for the synthetic iron-carbon alloy, $\mathrm{F}_{3}$, with those for the commercial carbon steel $\mathrm{C}_{24}$, having the same carbon content, with silicon and manganese in addition, in approximately the same proportions as the nickel steels. The combined effect of these two elements, if the action of phosphorus and sulphur is considered inappreciable, is to lower the $\mathrm{Ac}_{1}$ and $\mathrm{Ac}_{3}$ ranges as seen from Table 2, 4 to $5^{\circ} \mathrm{C}$, and $\mathrm{Ac}_{2} 8^{\circ} \mathrm{C}$, while they lower the $\mathrm{Ar}_{1}$ transformation some $32^{\circ} \mathrm{C}$. The lowering of $\mathrm{A}_{1}$ and $\mathrm{A}_{3}$ is due to the manganese, but its full effect is neutralized by silicon, which has the opposing tendency to raise these critical ranges. It may be, however, that both elements contribute to the lowering of $\mathrm{Ac}_{2}$.

\section{INTERPRETATION AND APPLICATION OF EXPERI- MENTAL DATA}

The methods of obtaining the temperatures given for the $A_{3}$ transformation in hypoeutectoid steels are usually not completely specified, but in general the temperatures chosen are those corresponding to the maximum of the thermal change on the inverse-rate or derived differential heating curves. From the quenching experiments previously noted and recorded in Fig. 8 , it is evident that this point does not represent a temperature 
of homogeneous austenite solution, which exists only above a temperature some $20^{\circ} \mathrm{C}$ higher. This temperature corresponds closely with the point on the inverse-rate heating curves, here called the end of $\mathrm{Ac}_{3}$. This, then, is a fundamental temperature of heat-treatment practice readily determinable by the two most widely recognized methods of metallography, and which should therefore be the temperature sought in critical-range determinations for the uniformity and standardization of metallographic practice and of thermal-treatment specifications.

The curves of Fig. 8 then furnish the fundamental data for determining the heat treatment of 0.4 per cent $\mathrm{C}$, o to 4 per cent nickel steels, and for correcting such thermal observations

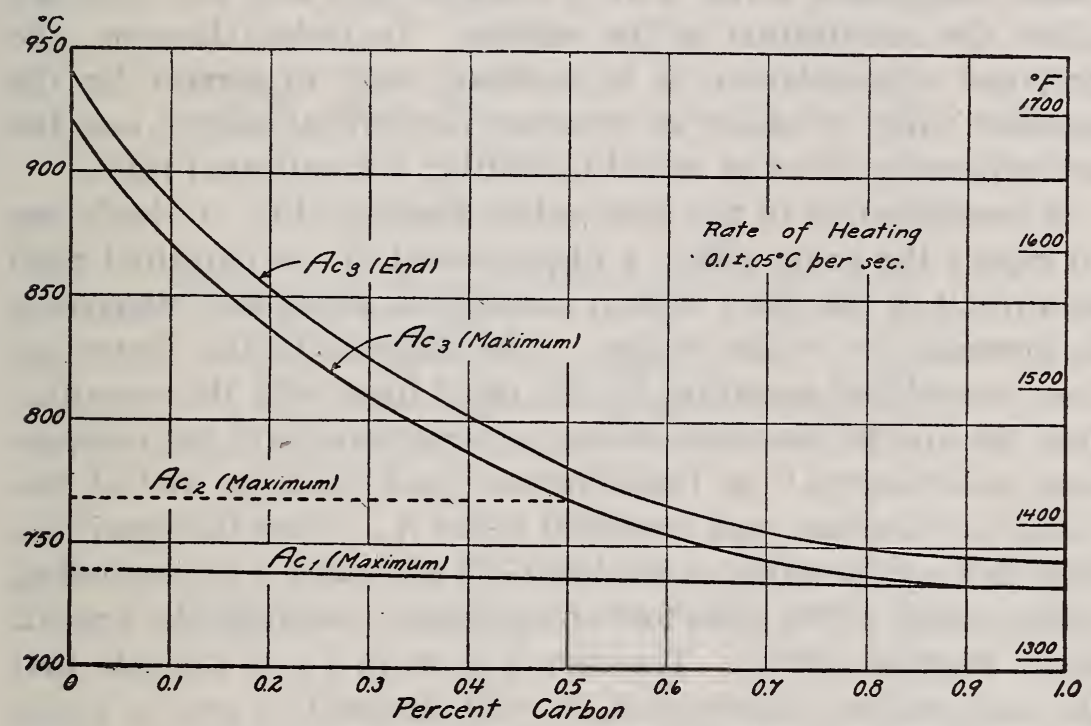

FIG. 9.-Effect of carbon on Ac critical ranges of carbon steels

as indicate only $\mathrm{Ac}_{3}$ maximum, but they do not furnish any guide to the treatment of steels differing much in composition from 0.4 per cent $C$. Since carbon has a much more pronounced effect on the $A_{3}$ ranges than nickel, it may be of some value to outline a method of extrapolation to higher or lower carbon contents with a satisfactory degree of accuracy.

Since any means of extrapolation may be expected to depend on the relation between the $A_{3}$ transformation and the carbon content of simple steels, the curves representing the critical ranges on heating pure iron-carbon alloys have been reproduced in Fig. 9. These are taken from unpublished data available at the Bureau of Standards and interpreted on the same basis as 
the curves presented here. The line representing the end of $\mathrm{Ac}_{3}$ agrees within $10^{\circ} \mathrm{C}$ with the observations of Howe and Levy ${ }^{12}$ on the microstructure of quenched specimens of low manganese steels; so from the preceding conclusions as to the effect of ordinary quantities of manganese and silicon on the Ac ranges its accuracy is established for carbon steels well within the limits required in commercial work.

From this curve, the effect of various carbon contents for a given nickel content may be readily estimated on the assumption that the curve does not lose its characteristic form for that nickel content. This assumption appears justifiable as nickel (or a nickel compound) forms a solid solution with iron and does not affect the constitution of the carbide. To make, therefore, the proposed extrapolations it is necessary only to correct for the familiar effect of nickel in lowering the critical ranges and the accompanying effect of nickel in shifting the eutectoid ratio.

A consideration of the iron-carbon diagram, Fig. Io, leads one to expect the latter effect, a displacement of the eutectoid ratio as a result of the effect of such elements as nickel and manganese in lowering the critical ranges. The diagram in this figure has been reproduced according to the usual form with the exception that the line $S E$ has been drawn to correspond with the independent observations ${ }^{13}$ of Tschischewsky and Schulgin, and of Saldaou, and Goerens, and extended below $A_{1}$. From this figure, it is seen that any lowering of the line GOS will cause a corresponding displacement of the eutectoid composition, providing the line $S E$ is not likewise shifted. The curves given in Fig. 8 indicate that the temperature difference, $A_{3}-A_{1}$, will diminish to zero in a 0.40 per cent $C$ steel with a nickel content of approximately 12 per cent. Hence such a steel should be of eutectoid composition, but this can not be verified directly by experiment, because a 12 per cent nickel steel is not pearlitic on slow cooling. It is of interest to note that $\mathrm{I} 2$ per cent nickel would lower $\mathrm{Ar}_{1}$ to $45^{\circ} \mathrm{C}$., which is in close proximity to the line $S E$ extended, of Fig. Io.

On the basis of the preceding considerations, it may be stated that the eutectoid composition is lessened by an amount equal to 0.042 per cent $\mathrm{C}$ for each I per cent nickel present, which agrees very closely with Bullens. ${ }^{14}$ Using this value in connection with

12 Howe and Levy, Trans. A. I. M. E., 47, p. 587; r9ז3.

13 Tschischewsky and Schulgin, J. Iron and Steel Inst., 95, p. 189; 1917. Saldaou and Goerens, Rev. de Met. 14, p. 65 ; I9I7.

14 Bullens, p. 304, Steel and Its Heat Treatment, John Wiley \& Sons. 
the curves of Fig. 9, a good approximation of the effect of carbon on the critical ranges, the nickel remaining constant, can be made by moving these curves to the left to correspond with the nickel content and down in proportion to the lowering effect of that content on $\mathrm{Ac}_{1}$ as given in Fig. 8. This has been done in Fig. II,

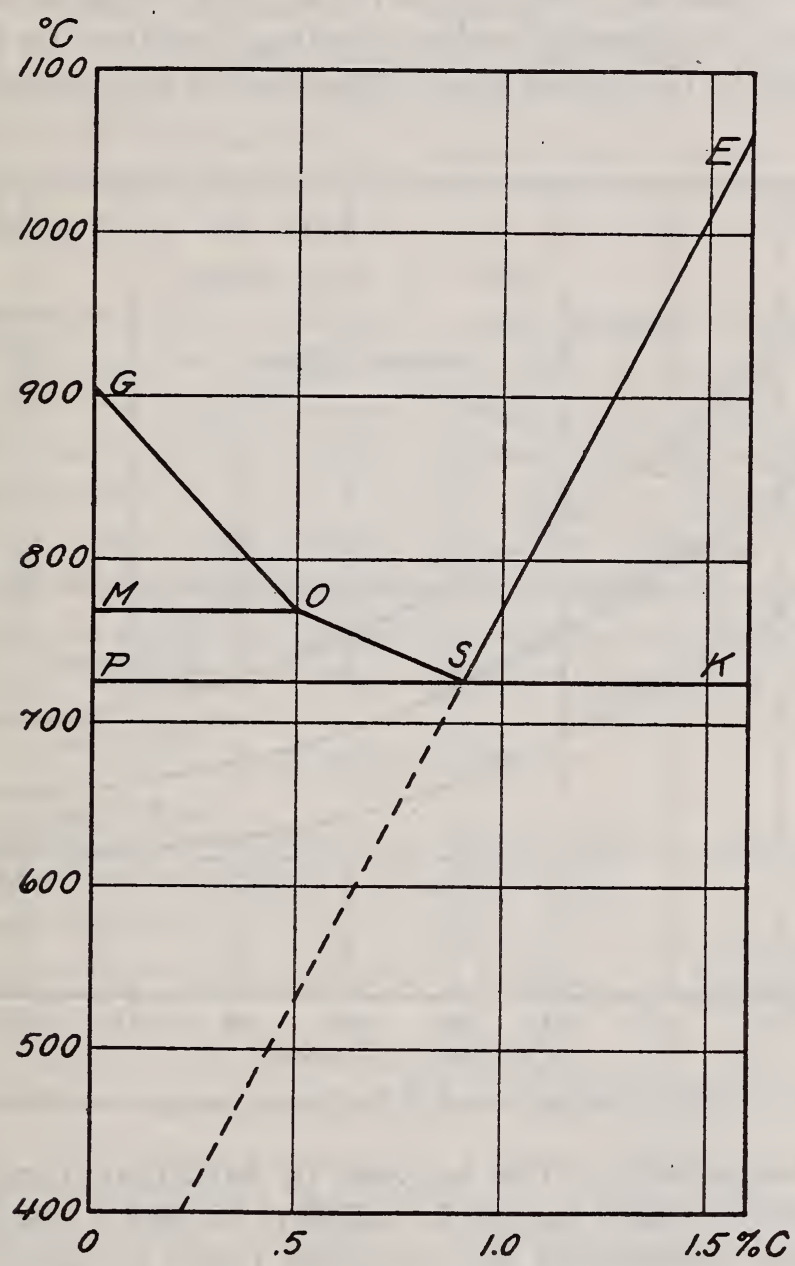

Fig. Io.-Iron-carbon equilibrium diagram, solid phases

the curves of which show the effect of carbon for 0,2 , and 4 per cent nickel (the last nickel content is extrapolated) on the end of the $\mathrm{Ac}_{3}$ range, except, of course, near the eutectoid compositions where the curves represent the end of $\mathrm{Ac}_{1}$. The justification for these idealized curves lies in their agreement with Honda's values of Fig. I for zero carbon and with the values here given for 0.40 
per cent $\mathrm{C}$, and for the eutectoid composition as represented by the $\mathrm{Ac}_{1}$ transformation.

The temperatures given for the end of the $\mathrm{Ac}_{3}$ ranges do not, of course, represent practical heat-treatment temperatures. These values are only a basis from which to estimate the proper hardening or annealing temperature for a given composition, which temperature is influenced under operating conditions by the mass of the steel to be treated and by the time it is subjected to the

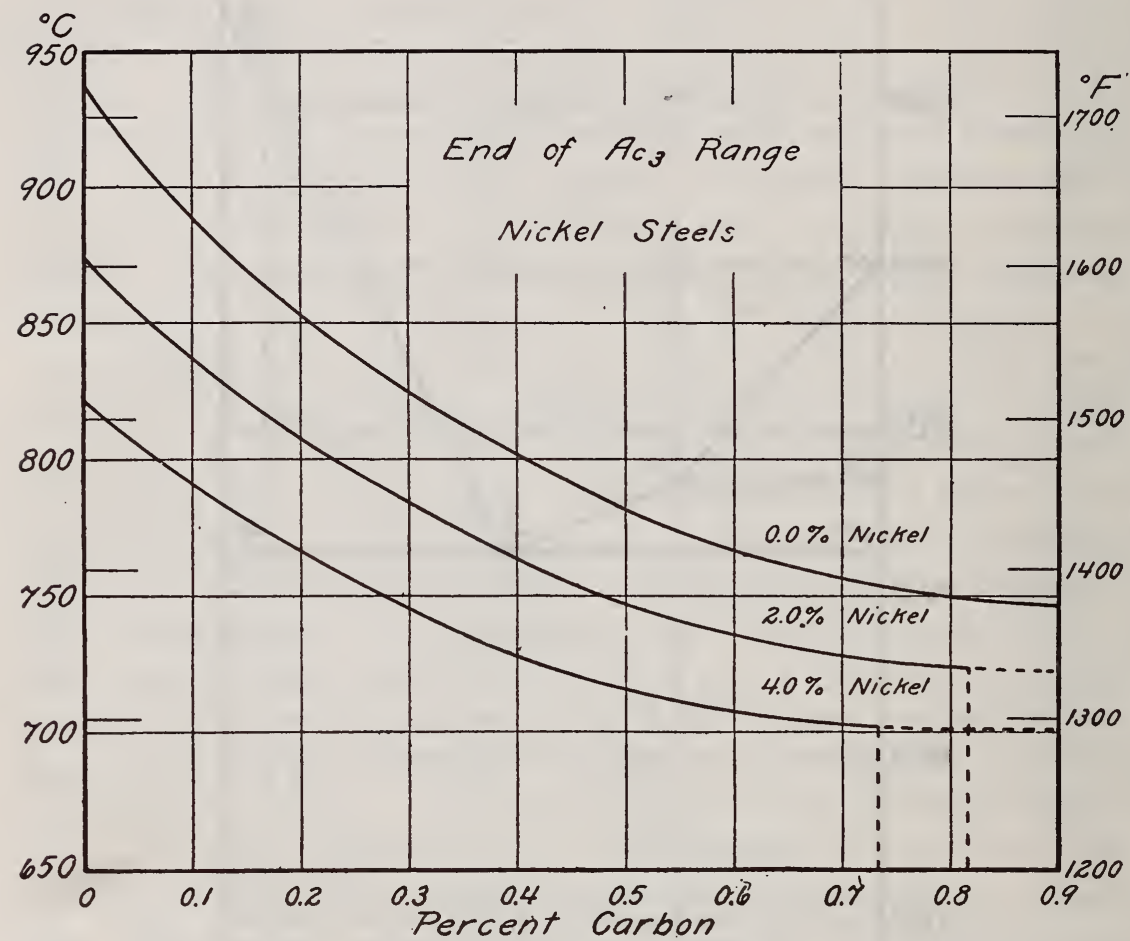

FIG. II.-Effect of carbon on end of $A c_{3}$ for 0,2 , and 4 per cent nickel

furnace temperature. The increase in hardening temperatures necessitated by these factors is sufficient to give a steep enough temperature gradient in the specimen being hardened by the time the Ar transformations are reached, to insure thorough hardening. There is, however, no general rule which covers the effect of mass and time.

The foregoing discussion has been on the basis of material of known composition. When, however, the composition is known to be only within the limits prescribed by certain specifications, allowance may be necessary for the variation of carbon within these 
limits, which is usually \pm 0.05 per cent $C$. This variation amounts to 15 to $20^{\circ} \mathrm{C}$ for a carbon content of 0.40 per cent and is increasingly larger for lower carbons, as Fig. II clearly shows. This would indicate that for uniformity of product the allowable variations in carbon content should be kept quite low, at least for steels of low carbon content. This use of too wide allowable limits in the specification of carbon content often leads to nonuniformity of product or much needless testing. Recently, for example, one of the Government departments has had to resort to testing a considerable quantity of formed bars for the purpose of classifying them into smaller groups according to the carbon content.

It might be noted in regard to this problem of classifying nickel steels that the thermal curves offer an accurate criterion for the carbon and nickel content of nickel steels, assuming other things constant, as there is only one carbon content for a given difference between $A_{3}$ and $A_{1}$, and one nickel content which corresponds to a given temperature of $A_{1}$. The position of $A r_{1}$ is of considerable commercial value in that it indicates the highest temperature at which the annealing operation can be arrested to substitute a more rapid cooling, thereby increasing the furnace output.

\section{SUMMARY}

The following conclusions were drawn from a survey of the work of previous investigators of nickel steels:

I. The critical ranges $\mathrm{Ac}_{3}$ on heating nickel steels have not been determined with as high a degree of accuracy as their industrial importance deserves.

2. The critical range $\mathrm{Ar}_{3}$ on cooling iron-nickel alloys is lowered nearly linearly to absolute zero for about 34 per cent nickel.

3. The critical range $A r_{1}$ and $A r^{\prime}$ of the pearlitic nickel steels is lowered with increasing nickel content until the region of complete martensitization is reached, when the transformation $\mathrm{Ar}^{\prime \prime}$ alone is found at a much lower temperature.

The critical ranges were determined for six commercial nickel steels of 0.30 to 0.40 per cent $\mathrm{C}, 0.55$ to 0.75 per cent Mn, 0.15 to 0.30 per cent $\mathrm{Si}$ contents, and nickel varying from o to 3.5 per cent, together with a pure iron-carbon alloy of 0.40 per cent $\mathrm{C}$ content. The data obtained appear to warrant the following conclusions:

(a) The point on the thermal heating curve designated as the end of $\mathrm{Ac}_{3}$ is the fundamental criterion of heat-treatment tempera- 
tures; it represents the temperature at which all the ferrite is in solution, as determined by quenching tests.

(b) The $\mathrm{Ac}_{3}$ range is shown most sharply on the thermal curves at slow rates of heating.

(c) The effect of the usual proportions of manganese and silicon on the Ac ranges is slight.

(d) Rate of temperature change has only a moderate effect on the temperature of the transformations over the range investigated.

(e) The position of the Ac ranges is more consistent than the Ar, due in part, at least, to the slighter effect of the previous structural condition.

(f) The $\mathrm{Ac}_{2}$ transformation is evident only in the two steels not containing nickel which are of 0.40 per cent $\mathrm{C}$ content, and is lower in the one containing appreciable manganese and silicon. A recalescence also is observed only in these steels.

(g) $\mathrm{Ac}_{1}$ is lowered by $10.5^{\circ} \mathrm{C}, \mathrm{Ar}_{1}$ by $21.5^{\circ} \mathrm{C}$, and the eutectoid ratio is decreased by approximately 0.042 per cent $\mathrm{C}$ for each I per cent nickel added.

The data given supply a basis for the direct specification of thermal-treatment temperatures of 0.40 per cent $\mathrm{C}$, o to 4 per cent nickel steels. Using the $\mathrm{Ac}_{3}$ range of carbon steels as a basis, an approximation is obtained of the effect of carbon, nickel constant. The effect of mass and time of heating must be considered in applying these data.

The 0.05 per cent $\mathrm{C}$ variation allowed in most nickel-steel specifications corresponds to a considerable variation in the $\mathrm{Ac}_{3}$ range, particularly for low-carbon contents.

The author is indebted to Misses H. G. Movius and P. L. Thompson for their competent aid in the experimental work.

WASHIngton, October I7, I9I9. 